\title{
Divergência genética entre cafeeiros do germoplasma Maragogipe
}

\author{
Janine Magalhães Guedes ( $\left.{ }^{1 *}\right)$; Diego Júnior Martins Vilela (1); Juliana Costa Rezende (2); \\ Felipe Lopes Silva ( $\left.{ }^{3}\right)$; César Elias Botelho (2); Samuel Pereira Carvalho (') \\ (') Universidade Federal de Lavras (UFLA), Departamento de Agricultura, Caixa Postal, 3037, 37200-000 Lavras (MG), Brasil. \\ (2) Empresa de Pesquisa Agropecuária de Minas Gerais, Unidade Regional do Sul de Minas, Caixa Postal, 176, 37200-000 Lavras (MG), Brasil. \\ (3) Empresa de Pesquisa Agropecuária de Minas Gerais, Unidade Regional da Zona da Mata, Campus UFV, $36571-000$ Viçosa (MG), Brasil. \\ (*) Autor correspondente: janine_guedes@yahoo.com.br
}

Recebido: 16/out./2012; Aceito: 13/jun./2013

\begin{abstract}
Resumo
Este trabalho objetivou identificar a divergência genética entre acessos de cafeeiro do grupo Maragogipe, situados no Banco Ativo de Germoplasma de Café do Estado de Minas Gerais, no município de Patrocínio (MG), por meio de análises multivariadas. Foram avaliados 27 descritores morfo-agronômicos, e a distância generalizada de Mahalanobis foi usada para quantificar a divergência genética entre os acessos. Como estratégias de agrupamento, foram empregados o agrupamento de Tocher, o método hierárquico Unweighted Pair-Group Method Using Arithmetic Averages (UPGMA) e a análise de variáveis canônicas. A análise de agrupamento pelos métodos de Tocher e UPGMA separaram os acessos em três e seis grupos, respectivamente. A análise da contribuição relativa de cada característica para a dissimilaridade genética destacou as características intensidade da ondulação da folha, quantidade de inflorescência por axila foliar e produtividade média como as que mais contribuíram para a obtenção da divergência genética. Observou-se que as três primeiras variáveis canônicas explicaram mais de $90 \%$ da variância total contida no conjunto das características analisadas. A combinação entre os acessos MG0167 e MG0170 é a mais promissora em um possível cruzamento para uso imediato em programas de melhoramento.

Palavras-chave: Coffea arabica, análise multivariada, melhoramento genético.
\end{abstract}

\section{Genetic divergence between coffee trees of the Maragogipe germplasm}

\section{Abstract}

This study aimed to identify the genetic divergence among coffee trees of the Maragogipe group in the active germplasm coffee bank in Patrocínio, Minas Gerais, Brazil, using multivariate analyzes. In the study, 27 morpho-agronomical descriptors were assessed. Mahalanobis generalized distance was applied to quantify the genetic divergence among genotypes. The following methods were used: Tocher clustering, Unweighted Pair-Group Method Using Arithmetic Averages (UPGMA) hierarchical clustering and the canonical variables analysis. The cluster analysis by Tocher method and the UPGMA separated the accessions into three and six groups, respectively. The analysis of the relative contribution of each characteristic to the genetic dissimilarity highlighted the intensity of curling leaf, inflorescence number per leaf axil and average yield as those that contributed most to the achievement of genetic divergence. It was observed that the first three canonical variables explained more than $90 \%$ of the total variance contained in the set of the analyzed characteristics. The combination between MG0167 and MG0170 accessions is the most promising for a possible crossing for immediate use in breeding programs.

Key words: Coffea arabica, multivariate analysis, genetic breeding.

\section{INTRODUÇÃO}

Bancos de germoplasma são de extrema importância para a manutenção e conservação de genótipos, pois servem de fonte de busca de genes desejáveis a serem introduzidos em programas de melhoramento genético. Diante disso, a completa caracterização dos acessos existentes em bancos de germoplasma facilita a identificação desses genes de interesse, de modo a fornecer parâmetros para a escolha de genitores favoráveis à obtenção de populaçôes segregantes em programas de hibridação (Costa et al., 2006).
O estudo da diversidade genética por meio de técnicas multivariadas é de primordial importância para o planejamento de programas de melhoramento e para a definição de estratégias de trabalho. Além disso, o conhecimento do grau de divergência genética possibilita o monitoramento dos bancos de germoplasma e gera informações úteis para preservação e uso dos acessos (Toquica et al., 2003).

Na predição da divergência genética, vários métodos multivariados podem ser aplicados, como a análise por componentes principais, por variáveis canônicas e os métodos aglomerativos. A escolha do método mais adequado deve ser realizada em função da precisão desejada, 
da facilidade de análise e da forma com que os dados foram obtidos (Cruz, Carvalho e Vencovsky, 2004).

A utilização de técnicas multivariadas para estimar a divergência genética tem se tornado comum e é empregada em vários trabalhos e em diversas culturas, tais como feijão (BonetT et al., 2006), soja (Matsuo et al., 2011), cúrcuma (Sigrist et al., 2011), mandioca (Vieira et al., 2011), café (Ivogro et al., 2008) e capim elefante (Shimoya et al., 2002).

Dentre os muitos acessos existentes no Banco Ativo de Germoplasma de Café do Estado de Minas Gerais, pode-se destacar o grupo Coffea arabica L. var. Maragogipe Hoert. ex Frohner, por ser uma planta mais rústica e apresentar porte, flores, frutos e sementes de dimensóes maiores, em comparação com outras variedades da mesma espécie. Além disso, possui bebida de qualidade superior, o que vem despertando grande interesse por parte dos melhoristas para possíveis cruzamentos (Mendes et al., 2008). Diante disso, este trabalho objetivou identificar a divergência genética para características morfológicas entre acessos de cafeeiros Maragogipe, pertencentes ao Banco Ativo de Germoplasma de Café do Estado de Minas Gerais, por meio de análises multivariadas.

\section{MATERIAL E MÉTODOS}

O Banco Ativo de Germoplasma de Café do Estado de Minas Gerais, pertencente à Empresa de Pesquisa Agropecuária de Minas Gerais, está instalado na Fazenda Experimental de Patrocínio, localizada na região do Alto Paranaíba (1859'26”S, 4858'9,5”W, $1.000 \mathrm{~m}$ de altitude). O solo é do tipo Latossolo Vermelho-Amarelo distrófico. O relevo da área do banco é de topografia plana, com ligeira inclinação. O clima do município de Patrocínio é classificado como Mesotérmico Subtropical Temperado, com chuvas de verão, inverno seco e verão quente (Wca), segundo Köppen (EMBRAPA, 2004).

Características morfológicas foram avaliadas em 12 acessos de cafeeiros do grupo Coffea arabica L. var. Maragogipe Hoert. ex Frohner. Esses acessos apresentam potencial de uso imediato no Programa de Melhoramento Genético do cafeeiro de Minas Gerais. Cada acesso foi composto de 20 plantas, divididas em duas repetiçóes. O delineamento experimental utilizado foi o de blocos ao acaso, sendo as parcelas experimentais compostas de dez plantas. O espaçamento utilizado foi $3,5 \times 1,0 \mathrm{~m}$ nas entrelinhas e entre plantas, respectivamente.

O manejo e a condução do banco de germoplasma foram realizados de acordo com as recomendaçóes técnicas para a cultura do cafeeiro. O manejo fitossanitário foi feito preventivamente ou curativamente, por meio de produtos químicos, acompanhando a sazonalidade da ocorrência de pragas e doenças.
Aos 30 meses após a implantação, os cafeeiros dos acessos foram avaliados de acordo com os principais descritores de cultivares de café arábica para a caracterização de cultivares registradas ou protegidas, passíveis de comercialização (Aguiar et al., 2004), conforme estabelecido pelo Serviço Nacional de Proteção de Cultivares (SNPC): planta (formato, altura, diâmetro de copa, comprimento do internódio das hastes e posição do ramo plagiotrópico), folha (largura, formato, cor da folha na fase jovem, intensidade de ondulaçáo da folha, profundidade da nervura secundária e domácia), flor (quantidade de inflorescência por axila foliar e quantidade de flor por inflorescência), fruto (tamanho de fruto e cor do fruto maduro), semente (comprimento da semente, largura de semente, espessura da semente e grau de aderência da película), ramo (intensidade da ramificação plagiotrópica e flexibilidade do ramo ortotrópico), peso de cem sementes e ciclo de maturação. Algumas características agronômicas adicionais também foram avaliadas neste trabalho: produtividade média (sacas de $60 \mathrm{~kg} \mathrm{ha}^{-1}$ ) do biênio 2009/2010 (Botelho et al., 2010), incidência e severidade de ferrugem (Pетек et al., 2006), incidência e severidade de cercosporiose (Petek e Patrício, 2007) e uniformidade média de maturaçáo (atribuídas notas às parcelas, anualmente, em escala de 1 a 3 , sendo: 1 - uniforme, 2 - medianamente uniforme e 3 - desuniforme).

Os dados foram submetidos à análise de variância, para avaliação da existência de variabilidade genética entre os acessos. Em seguida, empregaram-se as análises multivariadas, com o objetivo de agrupar os genótipos mais similares e identificar as principais variáveis para determinar a divergência genética entre os acessos, sendo elas: o algoritmo de agrupamento de Tocher, citado por RAO (1952), o método hierárquico Unweighted Pair-Group Method Using Arithmetic Averages (UPGMA) e a análise de variáveis canônicas.

Para o algoritmo de Tocher, utilizou-se como medida de dissimilaridade a distância generalizada de Mahalanobis $\left(\mathrm{D}_{\mathrm{iii}}^{2}\right)$, adotando-se o critério de que a média das medidas da divergência genética dentro de cada grupo deve ser menor que as distâncias médias entre quaisquer grupos (Cruz, Regazzi e Carneiro, 2004).

No método UPGMA, atribuiu-se, para o cálculo dos valores médios, sempre o mesmo peso aos dois elementos que estão sendo integrados. Como cada membro adicionado ao agrupamento tem o mesmo peso, os últimos elementos a se integrarem terão maior influência em relação aos primeiros (Ivoglo et al., 2008).

$\mathrm{Na}$ análise das variáveis canônicas, foram utilizadas as matrizes de variâncias e covariâncias fenotípicas e residuais entre os caracteres. Para a realização da análise, as médias originais dos caracteres foram transformadas por um processo de condensação pivotal, originando novas variáveis que se caracterizam por apresentar 
covariâncias residuais nulas e variâncias residuais iguais a um. Todas as análises foram realizadas utilizando-se o aplicativo computacional Genes (Cruz, 2008).

\section{RESULTADOS E DISCUSSÃO}

As medidas de dissimilaridade genética, estimadas pela distância generalizada de Mahalanobis $\left(\mathrm{D}_{\mathrm{ii}}^{2}\right)$ entre os pares de genótipos componentes dos 12 acessos estudados (Tabela 1), apresentaram magnitude variada (de 0,52 a 84,90 ), indicando a ampla diversidade genética entre alguns acessos e corroborando FonseCA et al. (2006), que encontraram magnitudes variando de 0,67 a 87,74 em clones de café conilon. Os acessos MG0170 e MG0167 foram considerados os mais dissimilares entre si, com uma distância genética de 84,99, com base na distância generalizada de Mahalanobis. Já os acessos MG0165 e MG0164 foram os mais similares, em razão de terem exibido a menor distância média entre os pares de distâncias estimadas $(0,52)$.

A variabilidade genética de uma populaçáo depende da divergência genética e dos pais envolvidos no cruzamento (Falconer, 1987). Porém, se o objetivo do programa é aumentar a produtividade, deve-se escolher, para cruzamentos, acessos de performance satisfatória que foram mais divergentes entre si ou que complementem alguma característica de um dos genitores. Os acessos MG0167 e MG0170 foram os que se mostraram mais divergentes $\left(\mathrm{D}_{\mathrm{ii}}^{2}=84,90\right)$, segundo a distância generalizada de Mahalanobis, fato confirmado com o resultado do agrupamento de Tocher (Tabela 2), que separou esses dois acessos em grupos distintos.

Houve a formação de três grupos pelo emprego do método de Tocher, sendo o primeiro deles subdividido em cinco subgrupos, de modo a facilitar a interpretação. O grupo I foi constituído por dez acessos, indicando que os possíveis cruzamentos entre genótipos desse grupo diminuem a possibilidade de obtenção de genótipos com características divergentes. O grupo II e o grupo III foram constituídos por apenas um acesso cada.
O número de grupos formados pelo método de Tocher demonstra a ampla variabilidade entre os acessos avaliados. Ivogro et al. (2008), trabalhando com progênies de café robusta, e FonSECA et al. (2006), trabalhando com clones de café conilon, obtiveram resultados semelhantes aos aqui citados.

Cruz, Regazzi e Carneiro, (2004) sugerem o não envolvimento de indivíduos de mesmo padrão de dissimilaridade nos cruzamentos, de modo a náo restringir a variabilidade genética e, assim, evitar reflexos negativos nos ganhos a serem obtidos para seleção.

Apesar da diversidade encontrada entre os acessos, de modo geral, interessam aos melhoristas apenas os acessos superiores em relação às características mais importantes e que apresentem divergência suficiente para gerar variabilidade nas populaçôes segregantes. Em programas de melhoramento genético de cafeeiro, busca-se um ideótipo cujo desempenho abranja, além de outras características, alta produçáo e aumento do tamanho do grão (Ferreira et al., 2005), sendo esta uma característica inerente do grupo Maragogipe.

O estudo da importância relativa das características para a divergência genética é de grande relevância, pois fornece estimativas para o descarte daquelas de menor importância para discriminação dos genótipos. Três características contribuíram com $43,2 \%$ da divergência genética, segundo o método de Daljit (1981), enquanto as 24 restantes contribuíram com 56,8\% (Tabela 3). Dentre todas as características analisadas, a intensidade de ondulação da folha $(10,1 \%)$, a quantidade de inflorescências por axila foliar (10,3\%) e a produtividade média (sacas de $60 \mathrm{~kg} \mathrm{ha}^{-1}$ ) do biênio 2009/2010 (22,7\%) foram as mais eficientes em explicar a dissimilaridade entre os acessos, corroborando os resultados encontrados por Ivoglo et al. (2008), que encontraram uma contribuição relativa de $10,5 \%$ para a característica produtividade média em café robusta.

Em virtude de as três primeiras variáveis canônicas explicarem mais de $90 \%$ da variância total contida no

Tabela 1. Dissimilaridade entre 12 acessos de cafeeiro Maragogipe em relação a 27 características agronômicas e morfológicas avaliadas, com base na distância generalizada de Mahalanobis $\left(\mathrm{D}_{\mathrm{ii}}^{2}\right)$

\begin{tabular}{|c|c|c|c|c|c|c|c|c|c|c|c|}
\hline Acessos & MG0164 & MG0165 & MG0166 & MG0167 & MG0168 & MG0169 & MG0170 & MG0171 & MG0172 & MG0173 & MG0174 \\
\hline MG0163 & 43,68 & 39,51 & 76,62 & 39,82 & 46,80 & 29,03 & 79,44 & 38,19 & 39,76 & 45,55 & 43,75 \\
\hline MG0164 & ---- & 0,52 & 12,71 & 8,33 & 10,83 & 14,15 & 48,52 & 2,91 & 9,67 & 2,79 & 9,14 \\
\hline MG0165 & & ----- & 15,10 & 9,44 & 10,65 & 12,33 & 46,75 & 2,91 & 8,25 & 2,25 & 11,03 \\
\hline MG0166 & & & ----- & 32,96 & 5,84 & 17,54 & 33,64 & 24,09 & 11,88 & 15,04 & 12,15 \\
\hline MG0167 & & & & ----- & 30,74 & 32,44 & 84,99 & 6,72 & 29,94 & 15,92 & 13,62 \\
\hline MG0168 & & & & & ----- & 4,42 & 24,40 & 19,59 & 2,04 & 11,42 & 10,74 \\
\hline MG0169 & & & & & & ----- & 18,08 & 17,92 & 2,83 & 10,86 & 14,52 \\
\hline MG0170 & & & & & & & ----- & 54,21 & 24,26 & 34,53 & 45,67 \\
\hline MG0171 & & & & & & & & ----- & 15,13 & 3,40 & 11,44 \\
\hline MG0172 & & & & & & & & & ----- & 8,05 & 13,45 \\
\hline MG0173 & & & & & & & & & & ----- & 12,96 \\
\hline
\end{tabular}


conjunto total das características analisadas $(92,6 \%$ da variância total acumulada), é possível explicar satisfatoriamente a variabilidade manifestada entre os acessos analisados, corroborando a formação dos três grupos de acessos, a partir do agrupamento de Tocher e da contribuição relativa pelo método proposto por DaLjIT (1981) (Tabela 4). Resultados semelhantes foram encontrados por Borges et al. (2008) em acessos de uva (88,7\%), por Costa et al. (2006) em cultivares de mamoeira $(99,0 \%)$ e por SUdRÉ et al. (2005) em acessos de pimenta e pimentão $(83,6 \%)$.

O método UPGMA permitiu a formação de 7 grupos entre os 12 acessos avaliados (Figura 1), similarmente aos resultados observados no método de Tocher, quando se efetuou um corte na posição 15 do eixo horizontal do dendrograma. Vale ressaltar que a distribuição dos indivíduos no dendrograma não segue um critério de formação de grupos, uma vez que o principal aspecto desse método consiste nas ramificaçôes que são obtidas (Cruz, Carvalho e Vencovsky, 2004). Os indivíduos

Tabela 2. Grupos formados de acordo com o método de Tocher, baseado na distância $\left(\mathrm{D}_{\mathrm{iii}}^{2}\right)$ de Mahalanobis, de 12 acessos de Maragogipe avaliados no Banco Ativo de Germoplasma de Café do Estado de Minas Gerais

\begin{tabular}{|lccccc|}
\hline Grupo & Subgrupo & \multicolumn{4}{c|}{ Acessos } \\
& 1 & MG0164 & MG0165 & MG0173 & MG0171 \\
\hline I & 2 & MG0168 & MG0172 & MG0169 & \\
& 3 & MG0166 & & & \\
& 4 & MG0174 & & \\
II & 5 & MG0167 & & \\
III & & MG0170 & & \\
\hline
\end{tabular}

Tabela 3. Contribuição relativa de 27 caracteres avaliados para a dissimilaridade genética de 12 acessos de Maragogipe pelo método proposto por DALJIT (1981)

\begin{tabular}{lccccc} 
Caracteres & $\begin{array}{c}\text { Valor } \\
\text { em } \%\end{array}$ & Caracteres & $\begin{array}{c}\text { Valor } \\
\text { em } \%\end{array}$ & Caracteres & $\begin{array}{c}\text { Valor } \\
\text { em \% }\end{array}$ \\
\hline FOR & 0,6 & SGA & 3,0 & PRF & 2,9 \\
\hline ALT & 0,9 & IRP & 4,7 & DOM & 6,5 \\
\hline DIA & 1,1 & FRO & 1,2 & INA & 10,3 \\
\hline HAS & 4,4 & PCS & 2,8 & FLQ & 2,3 \\
\hline POS & 1,5 & PRO & 22,7 & FRT & 1,7 \\
\hline LAF & 1,4 & FER & 4,5 & FCM & 6,1 \\
\hline FOF & 0,8 & CER & 0,2 & CSE & 0,5 \\
\hline CFJ & 2,9 & EPO & 0,4 & LSE & 0,6 \\
\hline INT & 10,2 & UNI & 1,8 & ESE & 4,4
\end{tabular}

FOR: formato de folha; ALT: altura de planta $(m)$; DIA: diâmetro de copa $(m)$; HAS: comprimento do internódio das hastes (principal e lateral); POS: posiçáo do ramo plagiotrópico em relaçấo ao ortotrópico; LAF: largura da folha; FOF: forma da folha; CFJ: cor da folha na fase jovem; INT: intensidade de ondulaçáo da folha; SGA: grau de aderência da película; IRP: intensidade de ramificação plagiotrópica; FRO: flexibilidade do ramo ortotrópico; PCS: peso de 100 sementes (g); PRO: produtividade média (sacas de $60 \mathrm{~kg} \mathrm{ha}^{-1}$ ) do biênio 2009/2010; FER: incidência e severidade de ferrugem em 2009; CER: incidência e severidade de cercosporiose em 2009; EPO: ciclo até a primeira produçáo após o plantio; UNI: uniformidade média de maturaçăo; PRF: profundidade da nervura secundária; DOM: domácia; INA: quantidade de inflorescências por axila foliar; FLQ: quantidade de flor por inflorescência; FRT: tamanho de fruto; FCM: cor do fruto maduro; CSE: comprimento da semente; LSE: largura da semente; ESE: espessura da semente. são agrupados aos pares, utilizando-se médias aritméticas da dissimilaridade, sendo que o dendrograma prioriza os genótipos com maior similaridade.

O primeiro grupo foi formado pelos acessos MG0164, MG0165, MG0173 e MG 0171. Os acessos MG0166, MG0170 e MG0163 permaneceram isolados, corroborando os resultados obtidos pelo método de Tocher (Tabela 2).

Observa-se que os acessos MG0167 e MG0170 localizaram-se em grupos diferentes, tanto pelo método de Tocher quanto pelo agrupamento UPGMA, além de terem apresentado a maior distância genética, apresentando, assim, grande divergência entre eles. Da mesma forma, IVOGLo et al. (2008) e Sudré et al. (2005), em café e pimenta, respectivamente, também observaram a formação de grupos distintos quando foi utilizado o método UPGMA.

Desse modo, esses acessos reunidos em grupos mais distantes, que apresentaram maior dissimilaridade entre si, podem ser considerados como promissores em futuros cruzamentos artificiais.

Tabela 4. Estimativas das variâncias (autovalores) e variâncias acumuladas (percentuais) das variáveis canônicas, visando estimar a dissimilaridade genética entre 12 acessos de cafeeiro Maragogipe

\begin{tabular}{lrc}
$\begin{array}{l}\text { Variáveis } \\
\text { canônicas }\end{array}$ & $\begin{array}{c}\text { Autovalores } \\
\text { (variâncias) }\end{array}$ & $\begin{array}{c}\text { Variâncias } \\
\text { acumuladas (\%) }\end{array}$ \\
\hline 1 & 5596065,15 & 49,63 \\
\hline 2 & 3744084,21 & 82,84 \\
\hline 3 & 1102103,61 & 92,62 \\
\hline 4 & 611885,70 & 98,04 \\
\hline 5 & 166118,30 & 99,52 \\
\hline 6 & 30466,79 & 99,79 \\
\hline 7 & 11111,40 & 99,89 \\
\hline 8 & 7554,04 & 99,95 \\
\hline 9 & 2811,85 & 99,98 \\
\hline 10 & 1057,72 & 99,99 \\
\hline 11 & 836,57 & 100,00 \\
\hline
\end{tabular}

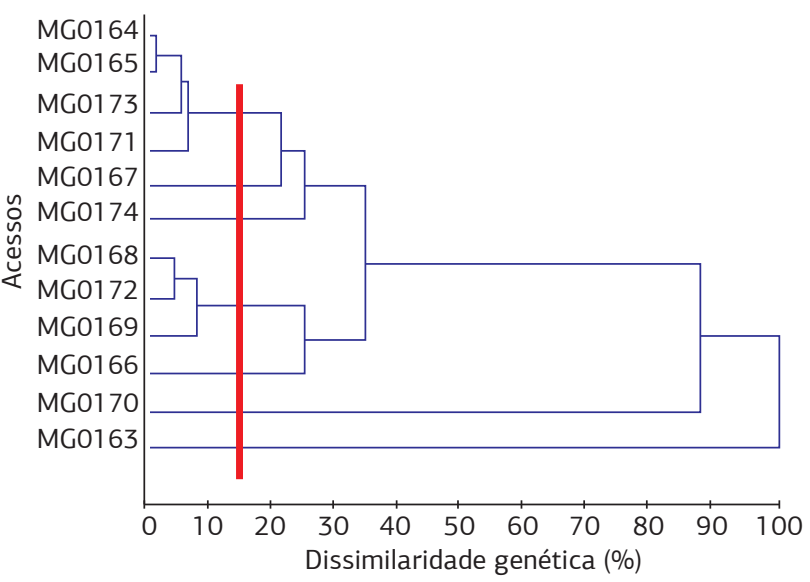

Figura 1. Dendrograma representativo da dissimilaridade genética entre os 12 acessos obtidos pela técnica Unweighted PairGroup Method Using Arithmetic Averages (UPGMA), utilizandose a distância generalizada de Mahalanobis como medida de dissimilaridade, sendo a linha vermelha indicativa do corte a $15 \%$. 


\section{CONCLUSÃO}

Existe variabilidade genética entre os 12 acessos de Maragogipe avaliados no Banco Ativo de Germoplasma de Café do Estado de Minas Gerais. Os acessos MG0167 e MG0170 apresentaram grande divergência genética entre si e foram os mais indicados para integrar futuros cruzamentos, a fim de explorar a variabilidade genética presente no germoplasma de Maragogipe do Banco de Germoplasma de Minas Gerais.

\section{AGRADECIMENTOS}

À Fundação de Amparo à Pesquisa do Estado de Minas Gerais (FAPEMIG), à Secretaria da Ciência, Tecnologia e Ensino Superior de Minas Gerais, ao Polo de Excelência do Café (PEC/Café) e ao INCT-Café, pelo suporte financeiro ao projeto, ao Conselho Nacional de Desenvolvimento Científico e Tecnológico (CNPq), pela concessão de bolsa PNPD (JCR), e à Coordenação de Aperfeiçoamento de Pessoal de Nível Superior (CAPES), pela concessão da bolsa PNPD Institucional (JMG).

\section{REFERÊNCIAS}

AGUIAR, A.T.E.; GUERREIRO-FILHO, O.; MALUF, M.P.; GALLO, P.B.E.; FAZUOLI, L.C. Caracterização de cultivares de Coffea arabica mediante utilização de descritores mínimos. Bragantia, v.63, p.179-192, 2004. DOI: 10.1590/S0006-87052004000200003

BONETT, L.P.; GONÇALVES-VIDIGAL, M.C.; SCHUELTER, A.R.; VIDIGAL FILHO, P.S. Divergência genética em germoplasma de feijoeiro comum coletado no Estado do Paraná, Brasil. Semina: ciências agrárias, v.27, p.547-560, 2006.

BORGES, R.M.E.; GONÇALVES, N.P.S.; GOMES, A.P.O.; ALVES, E.O.S. Phenotypic divergence among table grapes accesses in the Brazilian Semi-Arid. Pesquisa Agropecuária Brasileira, v.43, p.1025-1030, 2008. DOI: 10.1590/S0100-204X2008000800011

BOTELHO, C.E.; MENDES, A.N.G.; CARVALHO, G.R.; BARTHOLO, G.F.; CARVALHO, S.P. Seleção de progênies $\mathrm{F}_{4}$ de cafeeiros obtidas pelo cruzamento de Icatu com Catimor. Revista Ceres, v.57, p.274-281, 2010. DOI: 10.1590/S0034737X2010000300010

COSTA, M.N.; PEREIRA, W.E.; BRUNO, R.L.A.; FREIRE, E.C.; NÓBREGA, M.B.M.; MILANI, M.; OLIVEIRA, A.P. Divergência genética entre acessos e cultivares de mamoneira por meio de estatística multivariada. Pesquisa Agropecuária Brasileira, v.41, p.1617-1622, 2006. DOI: 10.1590/S0100-204X2006001100007

CRUZ, C.D. Programa Genes: Aplicativo computacional em genética estatística. Versão para Windows. Viçosa: Editora UFV, 2008.

CRUZ, C.D.; CARVALHO, S.P.; VENCOVSKY, R. Estudo sobre divergência genética. I. Fatores que afetam a predição do comportamento de híbridos. Revista Ceres, v.41, p.178-182, 2004.
CRUZ, C.D.; REGAZZI, A.J.; CARNEIRO, P.C.S. Modelos biométricos aplicados ao melhoramento genético, vol. 1. Viçosa: Editora UFV, 2004. p.171- 201.

DALJIT, S. The relative importance of characters affecting genetic divergence. The Indian Journal of Genetics and Plant Breeding, v.41, p.237-245,1981.

EMBRAPA. - Empresa Brasileira de Pesquisa Agropecuária. Centro Nacional de Pesquisa de Solos. Solos do Estado de Santa Catarina. Rio de Janeiro: Embrapa Solos, 2004. 726p. (Boletim de Pesquisa e Desenvolvimento, 46)

FALCONER, D.S. Introdução à genética quantitativa. Viçosa: Editora UFV, 1987. 279p.

FERREIRA, A.; CECON, P.R.; CRUZ, C.D.; FERRÃO, R.G.; SILVA, M.F.; FONSECA, A.F.A.; FERRÃO, M.A.G. Seleção simultânea de Coffea canephora por meio da combinaçáo de análise de fatores e índices de seleção. Pesquisa Agropecuária Brasileira, v.40, p.1189-1195, 2005. DOI: 10.1590/S0100-204X2005001200005

FONSECA, A.F.A.; SEDIYAMA, T.; CRUZ, C.D.; SAKAIYAMA, N.S.; FERRÃO, M.A.G.; FERRÃO, R.G.; BRAGANÇA, S.M. Divergência genética em café conilon. Pesquisa Agropecuária Brasileira, v.41, p.599-605, 2006. DOI: 10.1590/S0100204X2006000400008

IVOGLO, M.G.; FAZUOLI, L.C.; OLIVEIRA, A.C.B.; GALLO, P.B.; MISTRO, J.C.; SILVAROLLA, M.B.; TOMA-BRAGHINI, M. Divergência genética entre progênies de café robusta. Bragantia, v.67, p.823-831, 2008. DOI: 10.1590/S0006-87052008000400003

MATSUO, E.; SEDIYAMA, T.; CRUZ, C.D.; OLIVEIRA, R.D.L.; OLIVEIRA, R.C.T.; NOGUEIRA, A.P.O. Genetic diversity in soybean genotypes with resistance to Heterodera glycines. Crop Breeding and Applied Biotechnology, v.11, p.304312, 2011. DOI: 10.1590/S1984-70332011000400003

MENDES, A.N.G.; CARVALHO, G.R.; BOTELHO, C.E.; FAZUOLI, L.C.; SILVAROLLA, M.B. História das primeiras cultivares de café plantadas no Brasil. In: CARVALHO, C.H.S. (Ed.). Cultivares de café: origem, características e recomendaçóes. Brasília: Embrapa Café, 2008. p.157-226.

PETEK, M.R.; SERA, T.; SERA, G.H.; FONSECA, I.C.B.; ITO, D.H. Seleção de progênies de Coffea arabica com resistência simultânea à mancha aureolada e à ferrugem alaranjada. Bragantia, v.65, p.65-73, 2006. DOI: 10.1590/S0006-87052006000100009

PETEK, M.R.; PATRÍCIO, F.R.A. Cultivares resistentes ou tolerantes a fatores bióticos e abióticos desfavoráveis: ponto-chave para a cafeicultura sustentável. O Agronômico, v.59, p.39-40, 2007.

RAO, C.R. Advanced statistical methods in biometric research. New York: Willey, 1952.390p.

SIGRIST, M.S.; PINHEIRO, J.B.; AZEVEDO FILHO, J.A.; ZUCCHI, M.I. Genetic divergence among Brazilian turmeric germplasm using morpho-agronomical descriptors. Crop Breeding and Applied Biotechnology, v.11, p.70-76, 2011.

SHIMOYA, A.; CRUZ, C.D.; FERREIRA, R.P.; PEREIRA, A.V.; CARNEIRO, P.C.S. Divergência genética entre acessos de um 
banco de germoplasma de capim-elefante. Pesquisa Agropecuária Brasileira, v.37. p.971-980, 2002.

SUDRÉ, C.P.; RODRIGUES, R.; RIVA, E.M.; KARASAWA, M.; AMARALJÚNIOR,A.T. Divergênciagenética entre acessos de pimenta e pimentão utilizando técnicas multivariadas. Horticultura Brasileira, v.23, p.22-27, 2005. DOI: 10.1590/S0102-05362005000100005

TOQUICA, S.P.; RODRÍGUEZ, F.; MARTINEZ, E.; DUQUE, M.C.; TOHME, J. Molecular characterization by AFLPs of capsicum germplasm from the Amazon Department in Colombia. Genetic Resources and Crop Evolution, v.50, p.639-647, 2003. DOI: 10.1023/A:1024429320771

VIEIRA, E.A.; FIALHO, J.F.; FALEIRO, F.G.; BELLON, G.; FONSECA, K.G.; CARVALHO, L.J.C.B.; SILVA, M.S.; MORAES, S.V.P.; OLIVEIRA, C.M.; DENKE, M.L. Characterization of sweet cassava accessions based on molecular, quantitative and qualitative data. Crop Breeding and Applied Biotechnology, v.11, p.232-240, 2011. 